\title{
Desain Perekaman Basis Data Suara Ucap untuk Pengembangan Sistem Rekognisi Pengucap Otomatis Forensik Berbahasa Indonesia
}

\author{
${ }^{1}$ Angga Dwi Firmanto, ${ }^{2}$ Ivan Stefanus, ${ }^{3}$ Rifqi Ikhwanudin, ${ }^{4}$ Miranti Indar Mandasari \\ ${ }^{1}$ Fakultas Teknologi Industri, Institut Teknologi Bandung, 40312, Indonesia \\ 1anggafirmanto@students.itb.ac.id \\ 2ivanstefanus94@gmail.com \\ 3rifqi@ikhwanuddin.com \\ ${ }^{4}$ mandasari@tf.itb.ac.id
}

\begin{abstract}
Abstrak
Analisis rekognisi pengucap forensik sangat rutin diperlukan di Indonesia. Pengembangan sistem dari pendekatan fonetikakustik menuju sistem rekognisi pengucap otomatis yang tidak bergntung teks menjadi sangat penting untuk dilakukan. Dalam pengujian dan pelatihan kinerjanya, sistem rekognisi pengucap otomatis memerlukan suatu basis data. Makalah ini membahas mengenai desain perekaman basis data suara ucap yang terdiri dari tiga skenario utama, yaitu data suara ucap, wawancara, dan percakapan natural. Media perekaman yang digunakan berupa satu buah mikrofon dan lima buah media perekaman portabel dengan kualitas yang beragam. Adapun bahasa yang digunakan pada saat perekaman adalah Bahasa Indonesia. Basis data suara ucap berbahasa Indonesia ini diharapkan dapat menjadi alat untuk pengembangan sistem rekognisi pengucap otomatis di Indonesia, khususnya untuk aplikasi forensik.
\end{abstract}

Keywords: suara ucap, basis data, sistem rekognisi pengucap otomatis, Bahasa Indonesia

\section{Pendahuluan}

Pergerakan teknologi semakin pesat memacu teknik baru dalam dunia penyidikan. Penggunaan rekaman suara sebagai alat bukti digital menjadi salah satu upaya dalam penyelesaian pada beberapa kasus penyidikan. Sebagai alat bukti yang sah, sampel ucap digunakan dalam membuktikan identitas tersangka. Pada proses analisis, terdapat dua sampel yang dibandingkan, yakni sampel suara ucap yang dipertanyakan identitasnya atau dikenal dengan sampel unknown (UK), dan sampel suara ucap yang telah diketahui identitasnya atau sampel known (K). Pada umumnya, sampel UK berasal dari sadapan rekaman percakapan, sedangkan sampel $\mathrm{K}$ berasal dari rekaman suara tersangka ketika investigasi kasus dilaksanakan [1-2]. Dalam melakukan analisis pembuktian identitas tersangka dilakukan proses rekognisi pengucap (speaker recognition), yakni mengenali proses pengenalan identitas seorang pengucap dari sinyal suara ucap [3]. Penggunaan rekaman suara ucap sebagai alat bukti persidangan membuat pengembangan sistem rekognisi pengucap sangat diperlukan hal tersebut dikarenakan terdapat beberapa kasus korupsi dimana pelaku tidak dapat mengelak saat jaksa Komisi Pemberantasan Korupsi memperdengarkan rekaman ketika persidangan berlangsung [4].

Dilihat dari sejarahnya, sistem rekognisi pengucap telah mulai berkembang dan digunakan di dunia internasional setelah penemuan spectrogram suara ucap pada saat perang dunia ke-2. Spectogram merupakan representasi visual dari spektral frekuensi sinyal suara. Penemuan dari spektogram, diiringi dengan perkembangan dunia perekaman suara digital, membuat sumber teknologi terkait dengan sumber daya suara ucap berkembang dengan pesat. Salah satunya adalah dunia teknologi rekognisi pengucap [5]. Di Indonesia, penggunaan sistem rekognisi pengucap untuk identifikasi suara tersangka telah digunakan sejak tahun 2007 atau 2008. Ketika itu, Komisi Pemberantasan Korupsi (KPK) tengah menangani sebuah kasus penyuapan terhadap Urip Tri Gunawan, Ketua Tim Jaksa kasus Bantuan Likuiditas Bank Indonesia (BLBI), oleh Artalyta Suryani [6]. Dalam kasus tersebut, hasil analisis rekaman suara ucap dengan menggunakan sistem rekognisi pengucap digunakan sebagai salah satu bukti yang dihadirkan di persidangan [7,8]. Adapun model yang digunakan pada analisisnya adalah model source-filter menggunakan pendekatan akustik-fonetik dengan mengacu pada standar analisis forensik suara ucap dari Amerika Serikat [1].

Saat ini, banyak sekali kasus-kasus korupsi yang ditangani oleh KPK yang menggunakan rekaman suara ucap sebagai bukti persidangan. Oleh karena itu, permintaan akan analisis atau identifikasi suara ucap sangatlah banyak. Sebagai contohnya, Institut Teknologi Bandung (ITB) mendapatkan permintaan bantuan saksi ahli terkait identifikasi suara ucap secara rutin. Laboratorium Akustik Teknik Fisika di Fakultas Teknologi Industri (FTI) ITB bisa mendapatkan sekitar 1 permintaan kasus per bulan, dimana subjek pengucap yang harus dianalisis berkisar antara 1-8 subjek pengucap per kasusnya. Gambar 1 menunjukkan jumlah kasus permintaan analisis suara 
ucap per tahun, yang dapat kami himpun datanya sejak tahun 2012. Dapat dilihat pada gambar tersebut bahwa terdapat lonjakan jumlah permintaan analisis rekognisi pengucap pada tahun 2016. Meskipun fluktuatif, dapat diperkirakan bahwa jumlah permintaan kasus rekognisi pengucap akan terus bertambah seiring dengan kian gencarnya KPK dalam melakukan aksi pemberantasan kasus-kasus tindak pidana korupsi di Indonesia. Hal ini juga dapat dilihat dari data pada tahun 2017 pada caturwulan pertama, dimana telah terdapat 8 jumlah kasus yang dianalisis.

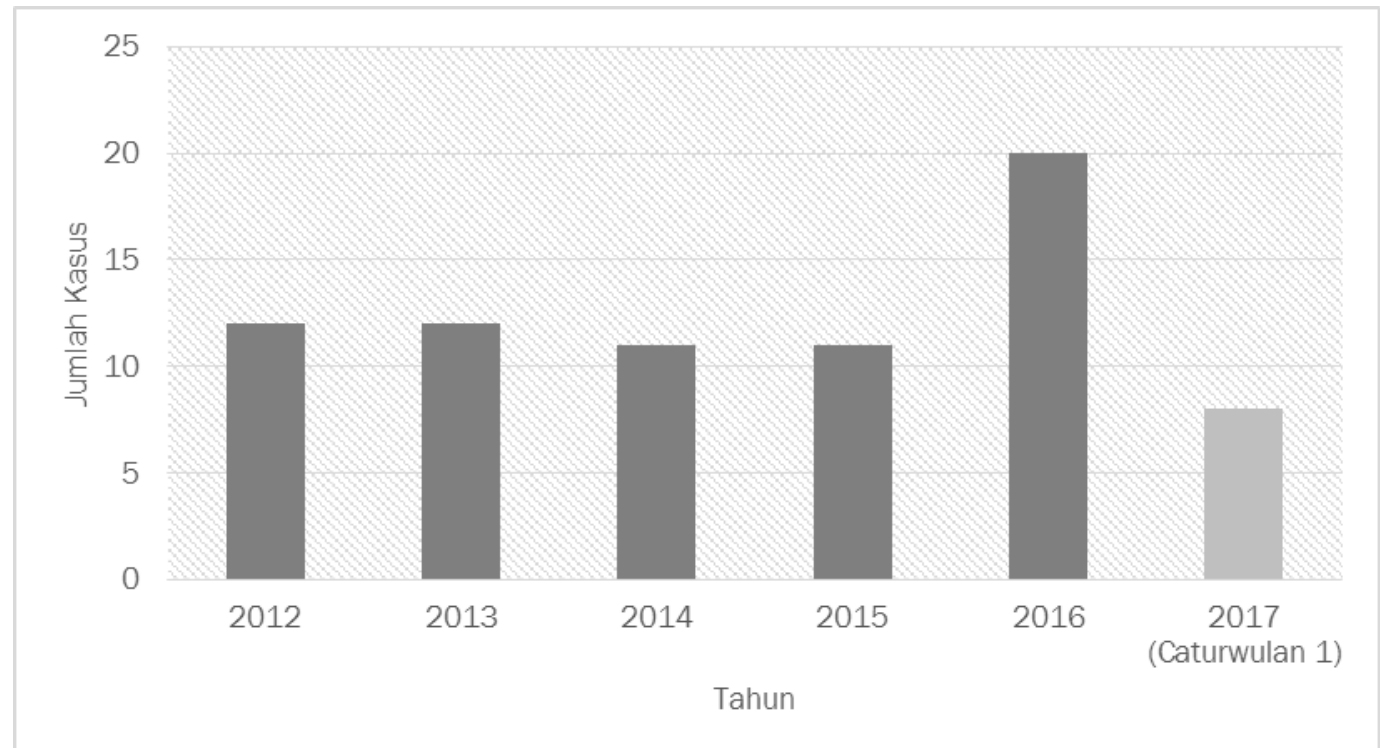

Gambar 1. Jumlah kasus permintaan analisis rekognisi pengucap dari tahun 2012 sampai 2017 Caturwulan pertama di Laboratorium Akustik Teknik Fisika, FTI-ITB.

Dengan perkiraan permintaan analisis rekognisi pengucap suara yang akan terus meningkat akan tetapi sekarang ini sistem rekognisi pengucap suara yang digunakan berbasis text-dependent. Pada sistem ini, dibutuhkan informasi dari konten ucapan. Sehingga proses analisis rekognisi pengucap memakan waktu yang cukup lama pada tahap pairing dan juga pada tahap tagging. Tahap pairing adalah tahap dimana konten ucap antara sampel UK dan sampel K dipasangkan. Sedangkan tagging merupakan proses pelabelan suara ucap dengan konten teks yang dibawanya. Dalam mengatasi permasalahan waktu analisis, diperlukan sistem rekognisi pengucap otomatis menggunakan pendekatan text-independent atau tidak bergantung teks sehingga tidak memerlukan proses pairing dan tagging [3,5,9].

Pembangunan basis data bertujuan untuk mendukung sistem rekognisi pengucap otomatis yang menggambarkan kasus forensik, kinerja yang baik diperlukan basis data dalam melatih dan menguji sistem. Basis data untuk keperluan forensik di Indonesia seharusnya menggunakan Bahasa Indonesia agar kinerja sistem tidak berkurang. Kinerja sistem akan berkurang jika Bahasa saat fase latihan dan fase uji berbeda [9-10]. Bahasa Indonesia merupakan serapan dari dialek melayu, dari berbagai suku dan Bahasa dari masing-masing suku di Indonesia yang beragam membuat aksen dari setiap individu memiliki aksen yang berbeda-beda namun memiliki kesamaan pola. Setidaknya terdapat 300 etnis yang tinggal pada 17,508 pulau dengan 365 bahasa daerah atau tidak kurang dari 669 dialek. Pada Bahasa Indonesia tidak ada perbedaan pada kata benda maupun kata sifat untuk masing-masing jenis kelamin dan kuantitas. Hal tersebut berlaku untuk kata kerja, kata kerja tidak berubah bentuk untuk menjelaskan sesuatu yang jamak. Untuk menuliskan sesuatu yang jamak digunakan pengulangan kata itu sendiri, sebagai contoh "anak" untuk tunggal sedangkan "anak-anak" untuk jamak [11].

Beberapa Basis data Bahasa Indonesia telah tersedia seperti Indonesian Database Corpus dan Indonesian Large Vocabulary Continous Speech (LVSCR) akan tetapi basis data tersebut difokuskan untuk rekognisi ucapan dan kurang mensimulasikan kondisi pada kasus forensik [12-13]. Pada makalah ini, membahas desain eksperimen pembangunan basis data suara ucap Bahasa Indonesia untuk keperluan forensik di Indonesia dimana pada skenario perekaman suara ucap diatur agar dapat mensimulasikan kondisi pada kasus forensik sebenarnya, basis data yang dibangun terdiri dari perekaman suara ucap dari responden dengan gaya bahasa yang khas natural dari personal responden [14]. 


\section{Desain Skenario Perekaman}

Dalam pengembangan sistem rekognisi pengucap suara diperlukan adanya basis data suara ucap. Proses pembuatan basis data perlu disimulasikan sesuai dengan kondisi sebenarnya. Oleh Karena itu, pada penelitian ini pengambilan data diatur dalam tiga skenario yaitu membaca data suara baca, wawancara dan percakapan natural. Pada penelitian ini, responden yang bersedia direkam data suara ucapnya tidak terbatas umur maupun jenis kelamin. Namun agar data suara ucap berdasarkan jenis kelamin memiliki kesamaan jumlah data, direncanakan agar rasio jumlah responden pria dan wanita sama. Semua responden yang berpartisipasi berada dalam keadaan sehat dan tidak berada dalam pengaruh obat-obat terlarang.

Dalam proses pengambilan data, terdapat tiga skenario yang dilakukan secara berurutan yaitu:

1. Suara baca

Dalam skenario ini terdapat tiga tahap. Tahap pertama responden diminta untuk membaca huruf vokal $\mathrm{A}$ / I / U / E / O sebanyak tiga kali. Kemudian responden untuk tahap kedua responden diinstruksikan membaca angka 0 (nol) / 1/2/3/4 / 5/6 / 7 / 8/9 sebanyak tiga kali. Selanjutnya pada tahap ketiga responden diminta untuk membaca artikel yang terdiri dari \pm 300 kata yang telah disediakan sebanyak satu kali.

2. Wawancara

Pada skenario wawancara ini, responden diberikan beberapa pertanyaan oleh peneliti mengenai hal umum. Skenario wawancara ini didesain untuk mensimulasikan saat kondisi investigasi sebenarnya.

3. Percakapan Natural

Untuk skenario percakapan natural, responden akan saling melakukan perbincangan dengan responden lain yang sebelumnya telah saling mengenal satu sama lain sehingga percakapannya berjalan secara natural. Percakapan dilakukan dalam kondisi dimana responden berada dalam ruang terpisah. Hal ini dirancang untuk mensimulasikan skenario percakapan via telepon yang terjadi pada hampir semua kasus forensik yang pernah ditangani.

Sebelum proses perekaman data, responden diwajibkan terlebih dahulu mengikuti Safety induction mengingat pentingnya safety dalam proses pengambilan data. Terdapat 9 poin pada konten safety induction untuk responden yaitu:

1. Jaga kebersihan selama pengambilan data.

2. Mohon melepas alas kaki di depan ruangan pengambilan data.

3. Hati-hati kaki terantuk saat memasuki ruangan pengambilan data \& hemi-anechoic.

4. Dilarang membawa makanan dan minuman ke dalam ruangan pengambilan data.

5. Selain peneliti dan responden dilarang memasuki ruangan pengambilan data, selain itu dimohon menunggu di ruang administrasi.

6. Dalam keadaan darurat, tetap tenang dan ikuti petunjuk peneliti untuk keluar melalui pintu utama.

7. Akses ruangan dan fasilitas yang relevan saja sesuai arahan peneliti.

8. Saat keluar ruangan hemi-anechoic mohon mendorong pintu pada bagian handel-nya.

9. Seminimal mungkin menyentuh wedges (dinding) pada ruangan semi-anechoic.

Setelah mengikuti safety induction, responden diharuskan mengisi form Biodata responden yang juga terdapat pernyataan bahwa responden bersedia mengikuti proses perekaman dan memperbolehkan rekaman suara ucapnya digunakan untuk keperluan penelitian. Daftar pertanyaan yang tertera pada form Biodata responden yaitu :

1. Nama :

2. Gender :

3. Tempat lahir :

4. Usia :

5. Keturunan / suku :

6. Provinsi / Kota asal (dibesarkan di) :

7. Pernah tinggal di :

8. Bahasa yang dikuasai (daerah dan asing) :

9. Kondisi Kesehatan : Sehat / Tidak Sehat (*coret yang tidak perlu)

10. Memiliki Logat khas : Ya / Tidak*

11. Kekentalan Logat (Lingkari angka berikut):
1 : hampir tidak terdengar
2 : sedikit terdengar
4 : jelas terdengar
3 : cukup terdengar
5 : sangat jelas terdengar (logatnya kental)

(*coret yang tidak perlu) 
Waktu yang diperlukan dari safety induction hingga pengambilan data secara detil dijelaskan pada Tabel 1. Dalam menyelesaikan perekaman data untuk 2 responden (1 pasang) dibutuhkan waktu kurang lebih selama 39 menit. Pertama-tama dilakukan tahap persiapan berupa safety induction, penjelasan singkat mengenai penelitian, dan pengisian biodata responden. Kemudian dilakukan pengambilan data terhadap masing-masing responden, secara bergantian, untuk ketiga skenario yang dirancang, yakni suara baca, wawancara, dan percakapan natural.

Tabel 1. Alokasi Waktu Pengambilan Data

\begin{tabular}{|c|c|}
\hline \multicolumn{1}{|c|}{ Kegiatan } & Waktu ( menit ) \\
\hline Tahap Persiapan ( untuk 2 orang responden ) : & 5 \\
\hline $\begin{array}{l}\text { Safety induction,_Penjelasan singkat mengenai Penelitian dan } \\
\text { Pengisian Biodata }\end{array}$ & \\
\hline $\begin{array}{c}\text { Tahap Pengambilan Data (Per Responden) : } \\
\text { 1. Suara Baca }\end{array}$ & $1 \times 2$ \\
\hline$\quad$ A / I U / E / O (3 kali) $/ 1 / 2 / 3 / 4 / 5 / 6 / 7 / 8 / 9 \quad$ kali) & $5 \times 2$ \\
\hline$\quad$ Membaca Artikel (1 kali) & $5 \times 2$ \\
\hline 2. Wawancara & $5 \times 2$ \\
\hline Total Waktu Perekaman data untuk 1 pasang ( 2 responden ) & 39 \\
\hline
\end{tabular}

\section{Konfigurasi Perangkat Perekaman}

Perekaman data suara ucap dilakukan di ruang semi anechoic chamber Laboratorium Akustik Adhiwijogo Gedung Center for Advanced Studies (CAS) ITB Bandung. Ruangan semi-anechoic atau tanpa gema sudah memadai untuk perekaman sampel suara ucap pada kondisi akustik yang terkontrol, tanpa adanya banyak gangguan bising dari dalam maupun luar ruangan perekaman. Perangkat perekaman yang digunakan terdiri dari:

1. Satu buah Laptop yang telah terinstalasi perangkat lunak Audacity untuk akuisisi data

2. Soundcard Steinberg $\mathrm{Cl}^{+}$

3. Mikrofon Shure SM58 untuk merekam suara ucap dari responden 1.

4. Media perekaman audio portabel
a. Sony IC-PX333
b. Olympus WS-853
c. Remax RP1
d. Zoom H2next
e. Handphone Lenovo A319 (2 buah)

Perangkat perekaman dan kondisi perekaman di ruang semi-anechoic digambarkan pada Gambar 2. Gambar tersebut menunjukkan gambar perangkat perekaman yang dikonfigurasikan di ruang perekaman semi-anechoic pada saat dilakukan proses pengambilan data. Selain itu, tampak pula pada gambar tentang kondisi perekaman responden ketika berada di dalam ruangan perekaman.

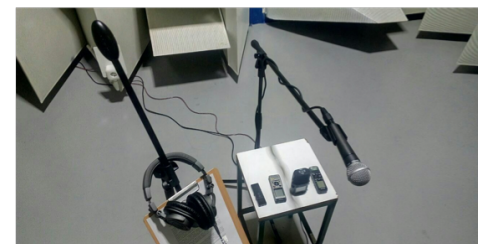

(a)

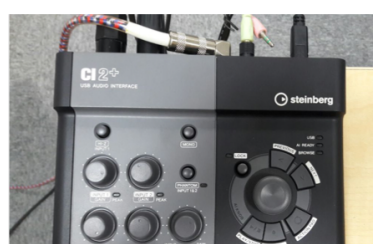

(b)

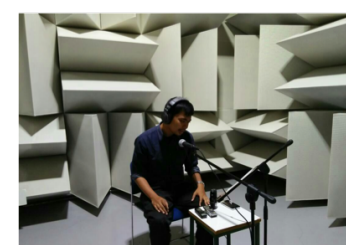

(c)

Gambar 2. (a) Perangkat perekam di ruang semi-anechoic (b) Soundcard Steinberg $\mathrm{C} 12^{+}$(c) Kondisi perekaman diruang semi-anechoic. 
Pada skenario percakapan natural, dua responden yang telah saling mengenal melakukan percakapan dalam ruang terpisah. Satu responden berada dalam ruang semi-anechoic dan satu responden berada dalam ruangan tanpa pengondisian. Konfigurasi perekaman diilustrasikan pada Gambar 3. Enam perangkat perekaman digunakan di dalam ruang semi-anechoic, yakni: 1 buah mikrofon, 4 alat rekam portabel, dan 1 buah telepon genggam. Di ruang operator, alat perekaman yang digunakan hanya 1 buah mikrofon dan 1 buah telepon genggam. Agar tercipta komunikasi dua arah pada kedua ruangan, masing-masing responden dan operator menggunakan perangkat headphone, yang juga terhubung dengan soundcard dan mikrofon.

Adapaun tahapan perekaman data suara ucap yang dilakukan adalah:

1. Mengaktifkan perangkat lunak Audacity untuk perekaman suara

2. Responden diminta untuk duduk tenang saat proses perekaman

3. Responden duduk rileks dan mendengarkan instruksi dari peneliti yang didengar melalui headset yang terpasang pada responden.

4. Semua alat perekaman dinyalakan antara lain mikrofon yang diatur dari perangkat lunak Audacity, Sony IC-PX333, Olympus WS-853, Remax RP1, Zoom H2next dan Handphone Lenovo A319.

5. Proses perekaman dimulai pertama dengan skenario suara ucap yaitu diawali membaca huruf vokal A / I / U / E / O sebanyak tiga kali, setelah itu membaca angka 0 (nol) / 1 / 2 / 3 / 4 / 5 / 6 / 7 / 8 / 9 sebanyak tiga kali dan juga membaca artikel yang terdiri dari \pm 300 kata. Selanjutnya mengikuti tahapan skenario wawancara dan proses perekaman berakhir setelah responden mengakhiri percakapan natural dengan responden lain yang telah dikenal sebelumnya.

6. Format file penyimpanan berupa .wav untuk media perekaman menggunakan mikrofon, perekam 1 dan perekam 4. Sedangkan untuk perekam 2 dan perekam 3 menggunakan format file MP3. Dan hasil perekaman pada perekam 5 berupa format .ogg.

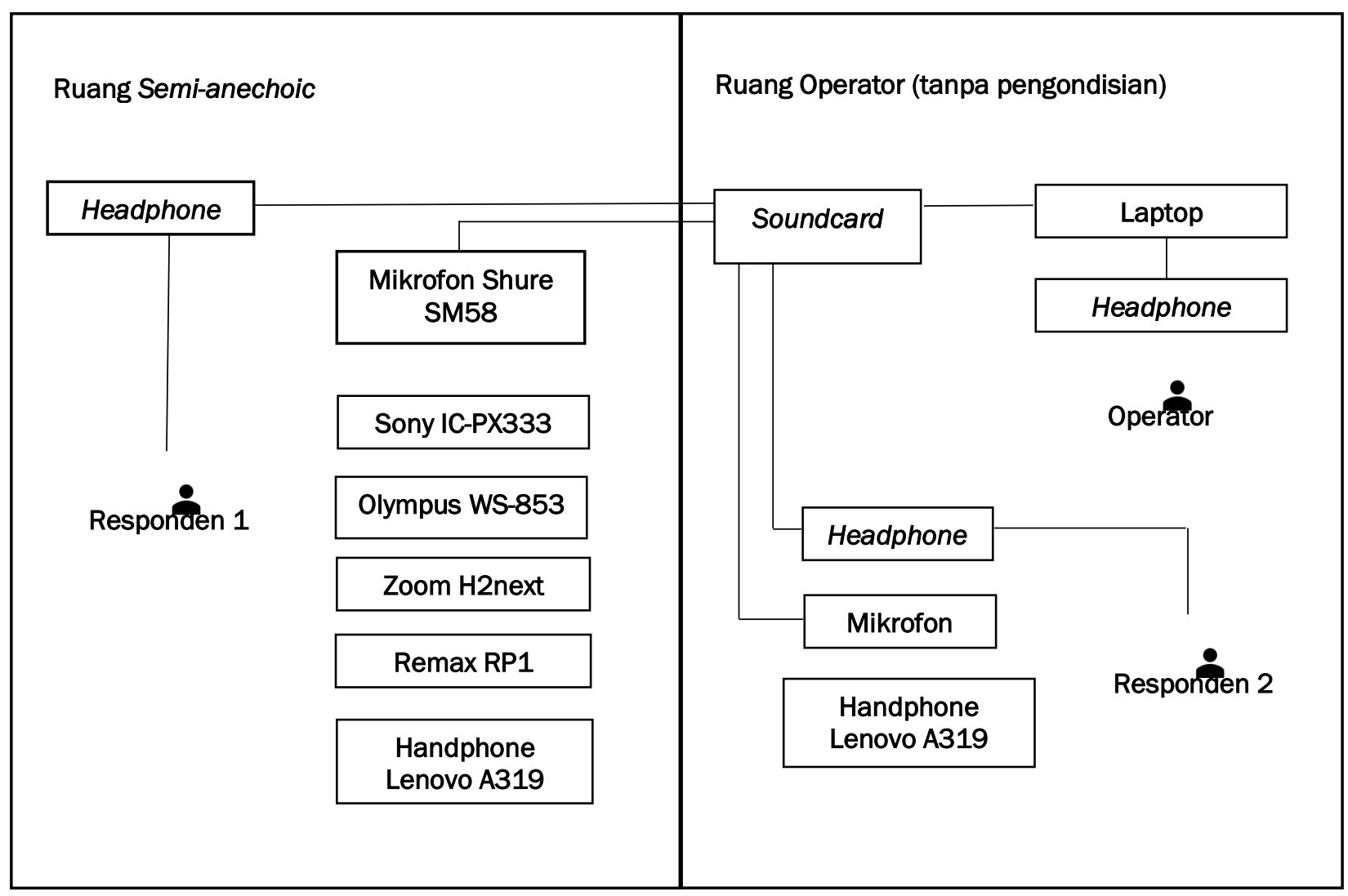

Gambar 3. Konfigurasi perangkat perekaman

\section{Analisis dan Diskusi}

Desain eksperimen pada penelitian ini merupakan pengembangan dari data penelitian sebelumnya oleh Stefanus, dkk [6]. Dimana penelitian tersebut membangun basis data Bahasa Indonesia dengan media perekaman mikrofon dan saat perekaman percakapan menggunakan jalur GSM (Global System for Mobile). 
Perangkat perekaman yang digunakan pada penelitian ini tidak hanya satu media perekaman, selain mikrofon juga menggunakan lima media perekam portabel yaitu Sony IC-PX333, Olympus WS-853, Remax RP1, Zoom H2next, Handphone Lenovo A319. Media perekaman dengan merek yang berbeda tersebut memilki respon dan kualitas perekaman yang berbeda-beda pula. Hal tersebut dapat menjadi bahan studi lanjut dalam melihat pengaruh berbagai macam media perekaman terhadap ciri Mel Frequency Cepstrum Coefficient (MFCC). Ruang perekaman juga berganti ke laboratorium baru, yakni di ruang semi-anechoic pada Laboratorium Akustik Adhiwijogo di Gedung Center for Advanced Studies (CAS), ITB.

Dari segi skenario, skenario merujuk pada penelitian Stefanus, dkk (2016). Perubahan terjadi pada konten skenario pembacaan angka. Pada penelitian tersebut responden diminta untuk membaca angka dari 1 - 10, sedangkan pada makalah ini, digit angka dirubah menjadi 0 - 9 dengan pengulangan sebanyak 3 kali. Sampai saat ini, sudah 17 responden yang terdiri dari 10 Wanita dan 7 Laki-Laki telah berpartisipasi mengikuti eksperimen ini dari target 200 responden. Penelitian sebelumnya [6] telah berhasil mengumpulkan sebanyak kurang lebih 80 responden.

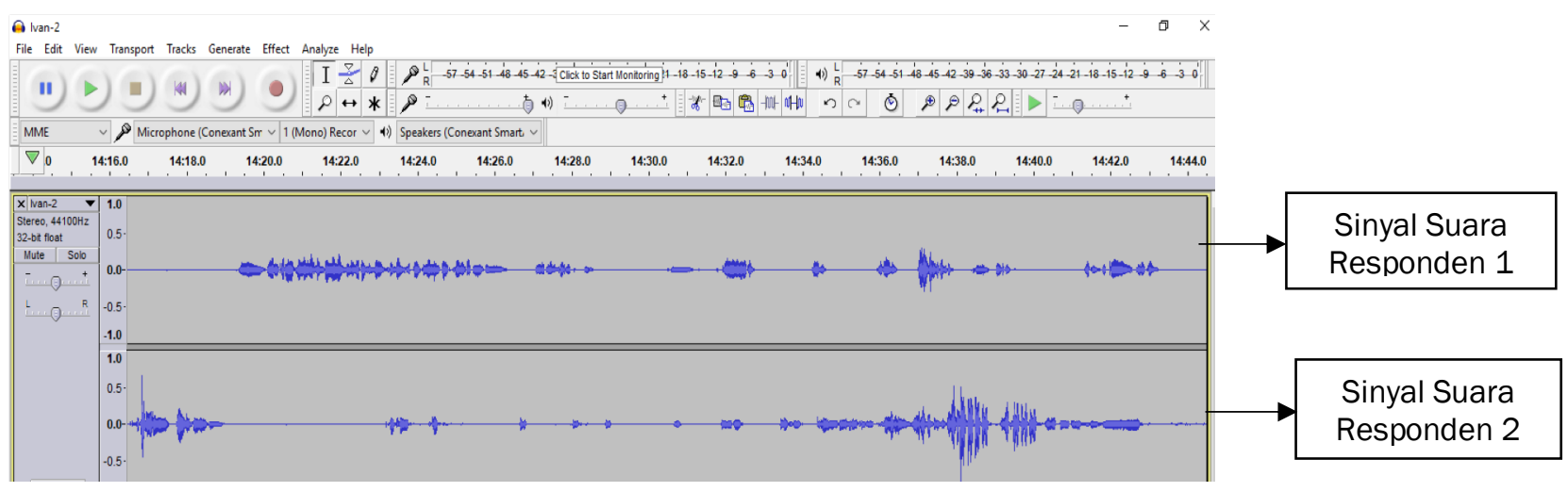

Gambar 4. Iampılan perekaman saat skenarıo percakapan.

Gambar 4 merupakan potongan tampilan saat perekaman skenario percakapan natural dari dua responden yang telah saling mengenal, percakapan natural berlangsung selama 5 menit. Proses perekaman memerlukan waktu 39 menit untuk sepasang (2 orang) responden. Rangkaian proses perekaman, dimulai dengan safety induction untuk memberi infomasi mengenai hal-hal yang perlu dilakukan jika ada suatu kondisi darurat dan hal-hal yang tidak boleh dilakukan saat proses perekaman.

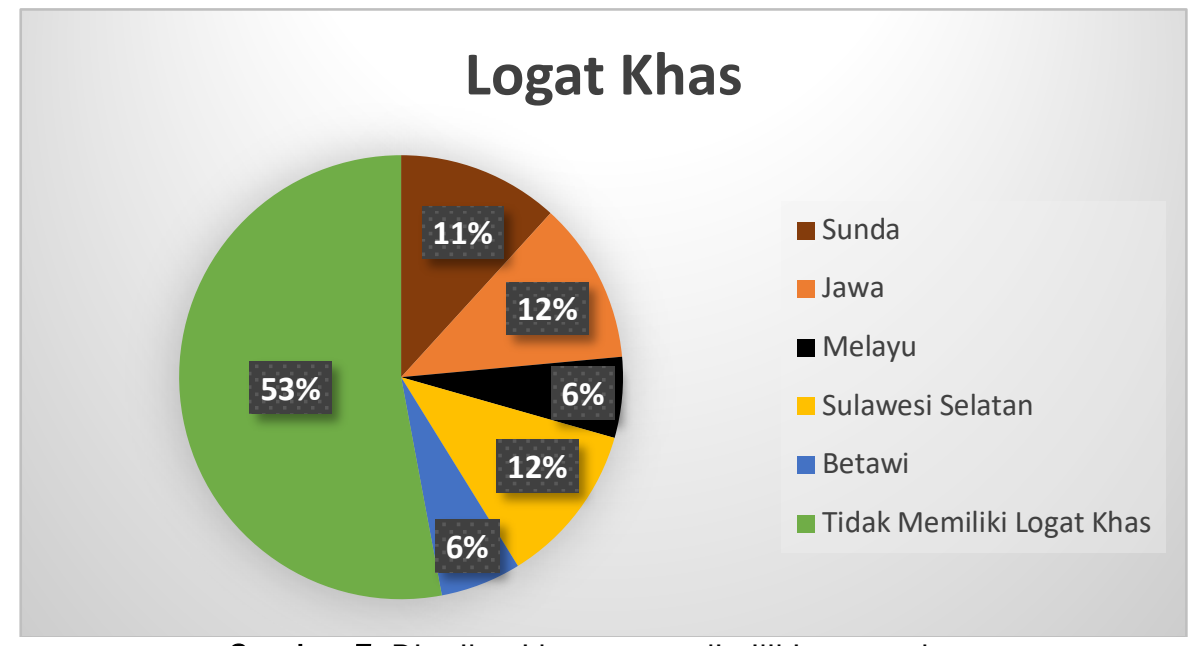

Gambar 5. Distribusi logat yang dimiliki responden.

Setelah itu, responden diminta untuk mengisi form biodata responden dengan konten yaitu usia, keturunan dan logat yang dimiliki. Detail mengenai proses perekaman dapat dilihat pada Bab 2 dan 3. Distribusi logat yang dimiliki dari responden ditunjukan pada Gambar 5, dimana telah terdapat distribusi sebaran logat Bahasa Indonesia yang cukup baik berdasarkan responden yang telah berhasil dihimpun sampai saat ini. 


\section{Kesimpulan}

Dalam penelitian ini, telah dilakukan eksperimen perekaman suara ucap dalam pengembangan basis data untuk keperluan rekognisi pengucap berbahasa Indonesia. Basis data didapatkan dari desain eksperimen menggunakan tiga skenario yang mensimulasikan kondisi pada kasus forensik. Basis data dari penelitian ini terdiri dari 17 suara ucap dari 17 responden dengan 7 Laki-Laki dan 10 Wanita. Dari 17 responden yang telah direkam suara ucapnya, masing-masing memiliki logat khas tersendiri dengan $53 \%$ responden tidak memiliki logat khas apapun, 12 \% memiliki logat Jawa, 12 \% memiliki logat Sulawesi Selatan, 11 \% memiliki logat Sunda, $6 \%$ memiliki logat Melayu dan $6 \%$ memiliki logat Betawi. Proses perekaman suara ucap semua dilakukan dengan dengan Bahasa Indonesia dalam memenuhi pengembangan sistem rekognisi suara ucap otomatis untuk kasus forensik di Indonesia. Perekaman data penelitian ini juga menggunakan lima media perekaman portabel, selain mikrofon, yaitu Sony IC-PX333, Olympus WS-853, Remax RP1, Zoom H2next, Handphone Lenovo A319. Dari setiap merek media perekaman memiliki respon dan kualitas rekaman berbeda sehingga dari hal tersebut dapat menjadi analisis lanjut mengenai pengaruh media perekaman terhadap ciri Mel Frequency Cepstrum Coefficient (MFCC) dari suara ucap manusia. Selanjutnya, pembangunan basis data akan dilanjutkan hingga mencapai 200 orang responden, sehingga dapat dibangun basis data yang baik untuk pengembangan sistem rekognisi pengucap otomatis di Indonesia, khususnya untuk aplikasi forensik

\section{Referensi}

[1] Sarwono, J., Mandasari M,I. \& Suprijanto. Forensic Speaker Identification: An Experience In Indonesians Court. Proceedings of 20th International Congress on Acoustics, Sydney, Australia, 23-27 August 2010.

[2] Mandasari, M.I. \& Sarwono, J. Studi pengaruh berbagai media perekaman terhadap ciri sinyal suara ucap untuk pengembangan sistem rekognisi pengucap otomatis. Usulan Penelitian Program Riset Peningkatan Kapasitas, Institut Teknologi Bandung. 2016

[3] Campbell, J P. Speaker Recognition : A Tutorial. Proceeding of the IEEE, vol.85, no.9, pp.1437-1462, September 1997.

[4] Mansyur \& Manurung, R.A.P. Alat Bukti Rekaman Suara Dalam Pembuktian Perkara Tindak Pidana Korupsi. Jurnal Komunikasi Hukum vol.3 no. 1. 2017

[5] Beigi, H. Fundamentals of Speaker Recognition. Springer. 2011.

[6] D. Maulana, Vonis 5 tahun untuk Artalyta, BBCIndonesia. Diakses tanggal 05-06-2017. http://www.bbc.co.uk/indonesian/news/story/2008/07/080729 artalytacase.shtml

[7] Percakapan Telepon Urip-Artalyta Asli, Detik News. Diakses tanggal 05-06-2017. http://news.detik.com/berita/984670/percakapan-telepon-urip-artalyta-asli.

[8] J. Sarwono, Tak Berkutik Karena Akustik (Dikutip dari: Yandi M.R. dan A. Sidharta, TEMPO Majalah Berita Mingguan, IImu dan Teknologi, 26/XXXVII 18 Agustus 2008). Diakses tanggal 05-06-2017, https://jokosarwono.wordpress.com/2008/08/23/tak-berkutik-karena-akustik/

[9] Stefanus, I. Perancangan Sistem Verifikasi Otomatis Untuk Forensik Suara Ucap Berbahasa Indonesia Menggunakan Gaussian Mixture Model. Master Tesis, Institut Teknologi Bandung, 2017.

[10] Stefanus, I., Mandasari, M.I. \& Sarwono, J. Development of Bahasa Speech Database for Speaker Recognition. Conference of The Oriental Chapter of International Committee for Coordination and Standarization of Speech Databases and Assessment Technique (O-COCOSDA), Bali, Indonesia, pp.277281, 26-28 Oktober 2016.

[10] Vloed, D.V.D., Bouten, J. \& van Leeuwen, D. NFI-FRITS : A forensic speaker recognition database and some first experiments. Odyssey. The Speaker and Language Recognition Workshop, pp. 6-13, 16-19 June 2014.

[11] Sakti, S., Hutagaol, P., Arman, A.A. \& Nakamura. Indonesia Speech Recognition for Hearing and Speaking Impaired People. INTERSPEECH - ICSLP, $8^{\text {th }}$ International Conference on Spoken Language Processing, Jeju Island, Korea, 4-8 Oktober, 2004.

[12] Sakti, S., Hutagaol, P. \& Arman, A.A. Development of Speech Corpus and Speech Recognition System for Indonesian Language. Research report Spoken Language Processing (SLP). 2004

[13] Sakti, S., Kelana, E., Riza, H., Sakai, S., Markov, K. \& Nakamura, S. Development of Indonesian Large Vocabulary Continous Speech Recognition System within A-STAR Project, Proceeding on Workshop on Technologies and Corpora for Asia-Pacific Speech Translation (TCAST) IJCNLP. 2008

[14] Morrison, G.S., Rose, P., Zhang, C. Protocol for the collection of database of recordings for forensic-voicecomparison research and practice. Australian Journal of Forensic Sciences, vol.44, no.2, pp.155-167, June 2012 